\title{
Complicações osteoarticulares da analgesia congênita
}

Osteoarticular complications of congenital analgesia

Fabiano Prata Nascimento', Edison Noboru Fujiki', Walter Yoshinori Fukushima', Gilberto Waisberg', Cleber Furlan', Mauro Gracitelli', Ricardo Tardini', Carlo Milani'

\section{Resumo}

Os autores apresentam dois irmãos com diagnóstico de analgesia congênita, com suas características clínicas e evolução. Essa doença é rara, apresenta alta morbidade e gera complicações osteoarticulares de difícil solução. 0 objetivo dos autores foi ressaltar a importância do diagnóstico tanto para 0 tratamento de suas afecções secundárias, quanto para seu aspecto jurídico.

Palavras-chave: Neuropatia hereditária motora e sensorial; insensibilidade congênita à dor; ortopedia.

\section{Abstract}

The authors present two brothers with congenital pain insensitivity, with their clinical characteristics and evolution. This disease is rare, has high morbidity and originates complex osteoarticular complications. The aim of the authors was to emphasize the value of the diagnosis for a better treatment and to avoid legal problems to the parents.

Keywords: Hereditary sensory and motor neuropathy; pain insensitivity, congenital, orthopedics.

Recebido: 20/6/2009

Revisado: 12/9/2009

Aprovado: 5/12/2009

\section{Introdução}

A analgesia congênita é uma desordem rara do sistema nervoso periférico e faz parte de um grupo de doenças de baixa prevalência, conhecidas como neuropatias autonômicas e sensitivas hereditárias (HSAN)1. Desde a descrição original de Charcot, em 1968, acerca da neuropatia sifilítica, as alterações da sensibilidade têm sido cada vez mais descritas pelos autores ${ }^{1}$. Em 1883, Morvan relatou uma série de pacientes que tinham em comum a diminuição de sensibilidade que poderia ser caracterizada como seringomielia ${ }^{1}$ Em 1986, $\operatorname{Jordan}^{2}$ descreveu as articulações neuropáticas em diabéticos. Em
1932, Dearborn ${ }^{3}$ reportou um caso que ele chamou "analgesia congênita pura generalizada". A insensibilidade congênita em crianças tem sido descrita desde então por diferentes autores, classificandose em diferentes tipos, de acordo sua apresentação clínica. Além das HSAN, outros distúrbios podem levar à analgesia, tais como: neuropatia diabética, tabes dorsalis, lepra, lesões periféricas nervosas, paraplegias, alcoolismo, lesões vasculares do lobo parietal, seringomielia, déficit mental e distúrbios psicológicos² ${ }^{2}$ Devido à diversidade das manifestações clínicas e etiológicas das alterações neuropáticas, tem-se como objetivo descrever as características clínicoepidemiológicas da analgesia congênita. 
Trata-se de relato de caso do serviço de Ortopedia da Faculdade de Medicina do ABC (FMABC) avaliado no período de julho a setembro de 2003. Os menores foram atendidos por livre demanda e acompanhados até o desfecho das complicações. Este relato foi autorizado pelo Comitê de Ética da FMABC (Parecer nº 039/2005).

\section{Descrição do Caso - $1^{0}$ Paciente}

Paciente do sexo masculino (Figura 1A), seis anos, branco, natural e procedente de Santo André (SP), nascido de parto normal, com $3.370 \mathrm{~g}$ e $53 \mathrm{~cm}$ após gravidez complicada (internação aos sete meses de gestação por sangramento e cólica de forte intensidade), com queixa de edema e hiperemia no pé direito há três semanas, com piora progressiva. Após três

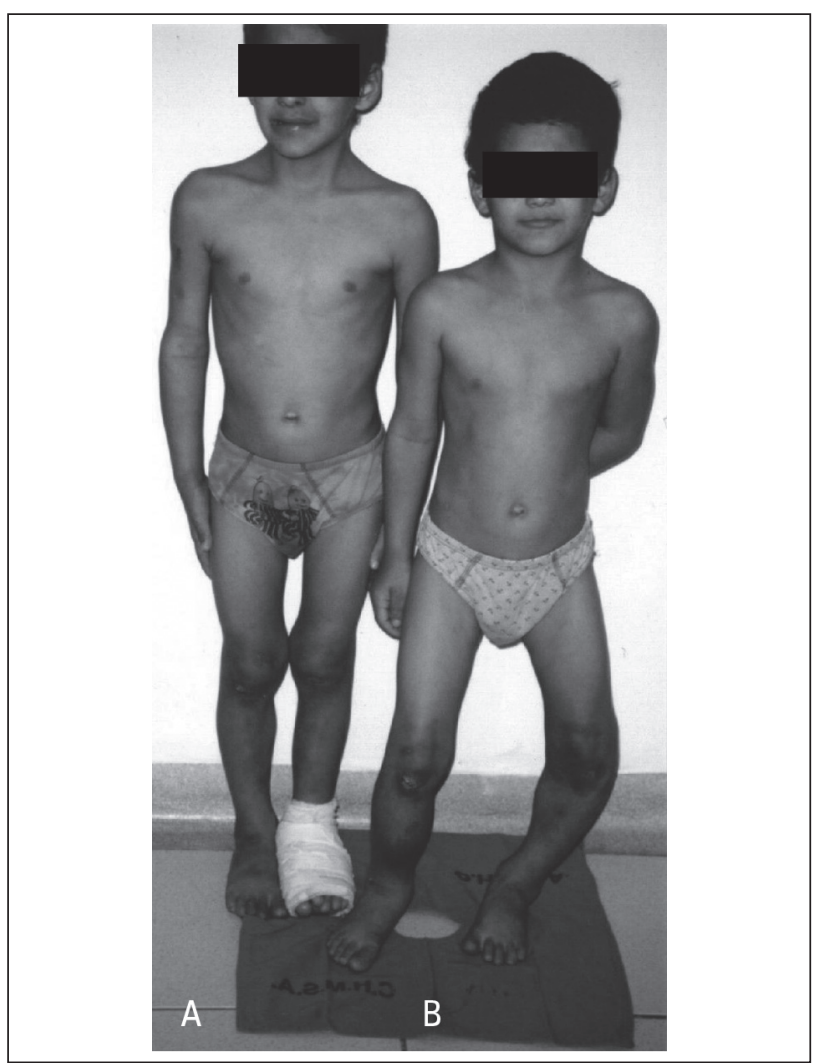

Figura 1 - (A) Paciente W.A.C.: sexo masculino, seis anos, cor branca; (B) Paciente G.A.C.: sexo masculino, quatro anos, cor branca.

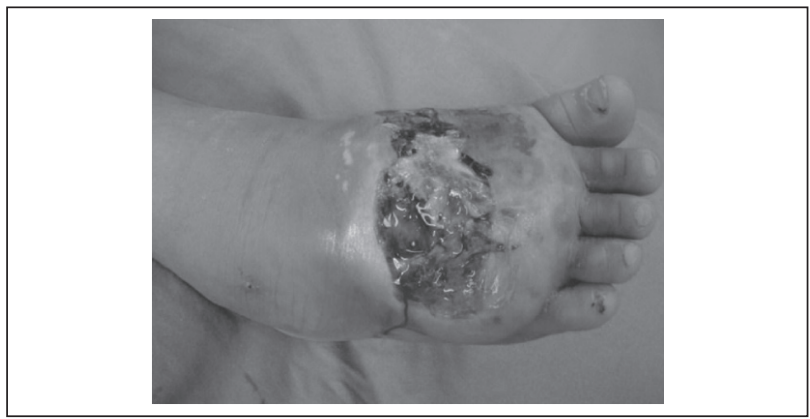

Figura 2 - Paciente A. Lesões bolhosas com presença de abundante secreção purulenta. dias de sua apresentação no pronto-socorro, evoluiu com febre (entre 38 e $39^{\circ} \mathrm{C}$ ) e aparecimento de lesões bolhosas no pé direito, com saída de abundante secreção purulenta (Figura 2). O paciente negava dor local. Havia uma semana, fazia uso de penicilina benzatina e Rocefin ${ }^{\circledR}$.

Mãe referiu que paciente não sentia dor desde o nascimento e que sofreu inúmeras lesões - involuntárias ou automutilação - em decorrência dessa alteração. Referiu que o filho se mutilava desde os três meses de idade, mordendo e arrancando a ponta dos dedos; informou, também, abscesso na mão esquerda aos nove meses de idade, com tratamento cirúrgico; arrancamento dos próprios dentes, sendo submetido à cirurgia bucomaxilar; múltiplos traumas e fraturas nos joelhos, pernas e pés; demora na cicatrização de até dois anos, devido ao paciente comer o próprio tecido de granulação; deformidade na articulação do joelho e do ombro; múltiplas escoriações na face, tronco e membros e lesões na mão esquerda, decorrente de queimadura aos quatro anos. Referiu também que desenvolvia picos febris frequentes, desde os nove meses de idade, acompanhados de astenia. Relatou sudorese, lacrimejamento e tato normal, hipersensibilidade ao estímulo frio diminuída ao calor. Negou dor visceral, mas referiu episódios esporádicos de fezes com sangue vivo. Afirmou que paciente apresenta bom raciocínio lógico, orientação e memória, manifestando nervosismo e ansiedade acentuada.

Irmão ( $2^{\circ}$ caso) possuía sinais e sintomas semelhantes, porém a mãe não apresentava alterações, e não foi possível obter informações do pai.

\section{Exame físico}

Paciente apresentava-se em regular estado geral, consciente, lúcido, contactuante, febril $\left(38^{\circ} \mathrm{C}\right)$ e descorado $(++/ 4)$. Ao exame dos membros, edema $+++/ 4$ de toda a circunferência do pé direito, com lesões bolhosas no seu dorso e saída de secreção purulenta. Hiperfrouxidão ligamentar presente em todas as articulações, escoriações em todo o corpo e deformidades em ambos os joelhos e ombros. Ausência de sensibilidade à dor, tanto na superfície quanto na profundidade e hipersensibilidade ao frio. Apresenta tato superficial e profundo normal, discriminação de pontos e propriocepção normal.

\section{Exames complementares}

- Hemograma: Hb: 7,40 g/dL, Ht: 24,40 \%; leucócitos: 36.840/mm (metamielócitos: 2\%; bastonetes: 19\%; segmentados: $55 \%$; eosinófilos: $2 \%$; linfócitos: $19 \%$; monócitos: $3 \%$ ); anisocitose ++ , microcitose ++ , hipocromia ++ . Obervação: leucocitose; neutrofilia com desvio à esquerda; linfopenia; hemáceas em alvo;

- Radiografia do pé direito: edema de partes moles e lesão osteolítica na base do $2^{\circ}$ metatarso (Figura 3);

- Radiografia da perna direita: fratura transversa na diáfise da tíbia com formação de calo ósseo (Figura 4);

- Eletroencefalograma: ritmo beta medicamentoso e desorganização difusa da bioeletrogênese cerebral para a faixa etária. 


\section{Evolução e tratamento}

Paciente acompanhado pela Ortopedia, Pediatria e Cirurgia Plástica, com diagnóstico inicial de analgesia congênita mais osteomielite aguda, abscesso no pé direito e anemia. Prescrito Rocefin ${ }^{\circledR}(100 \mathrm{mg} /$ $\mathrm{kg} / \mathrm{dia}$ ) de $12 / 12 \mathrm{~h}$, clindamicina $(10 \mathrm{mg} / \mathrm{kg} / \mathrm{dia}) \mathrm{de} 8 / 8 \mathrm{~h}$ por $10 \mathrm{dias}$, paracetamol na vigência de febre e infusão de uma bolsa de concentrado de hemáceas (após normalização da febre).

O paciente foi submetido a desbridamento e ressecção do material necrótico do pé direito, sendo também realizada a exérese do segundo metatarso, lavagem cirúrgica exaustiva e colocação de curativo oclusivo.

Após nove dias da primeira cirurgia, realizou-se novo desbridamento cirúrgico. Após 25 dias, foi submetido a outro desbridamento cirúrgico e recebeu alta hospitalar, sendo encaminhado para acompanhamento multidisciplinar.

Após dois meses da primeira cirurgia, paciente retornou para acompanhamento com regular estado geral, astenia, irritabilidade e afebril. A lesão apresentava-se com tecido de granulação adequado e sem sinais flogísticos.

\section{Descrição do Caso: $2^{0}$ Paciente}

Paciente do sexo masculino (Figura 1B), quatro anos, branco, natural e procedente de Santo André (SP), nascido de parto normal, com $3.330 \mathrm{~g}$ e $51 \mathrm{~cm}$. Gestação e parto sem intercorrências, com queixa de lesão de pele na região poplítea esquerda com secreção purulenta e piora progressiva após 15 dias de sua apresentação no pronto-socorro.

Mãe referiu fratura na tíbia esquerda ocorrida há um ano; múltiplas fraturas por autoagressão e deformidade nos artelhos. Também informou picos febris frequentes, sem comprometimento sistêmico, e episódio de hematêmese havia três meses. Relatou lesões ainda mais graves que do irmão por apresentar agitação e hiperatividade intensa. O paciente possuía déficit visual por autoagressão em ambos os olhos; bom desenvolvimento neurológico, apesar dos múltiplos traumas e lesões no crânio por bater a cabeça contra a parede frequentemente; sudorese e lacrimejamento normal. Negava dor visceral.

\section{Exame físico}

Paciente em regular estado geral, consciente, lúcido, contactuante, hiperativo, afebril, acianótico, anictérico, descorado $+/ 4$, hidratado. Apresentava múltiplas lesões cicatriciais na face e pescoço, cicatriz recente no crânio de $4 \mathrm{~cm}$ de extensão, diversas escoriações em ambas as pernas, tronco e cotovelos; joelho direito com acentuada angulação em varo (Figura 1B); encurtamento do membro inferior direito; deformidade no terço médio da tíbia esquerda; alteração da marcha e escoliose secundária à discrepância dos membros e lesão eritematosa com saída de secreção purulenta na região poplítea esquerda. Apresentava também hiperfrouxidão ligamentar, ausência de sensibilidade à dor, tanto superficial quanto em profundidade, e hipersensibilidade ao frio. Em algumas áreas manifestava dor, como a região proximal dos braços e das coxas. O tato e a propriocepção eram normais.

\section{Exames complementares}

- Hemograma: Hb: 8,90 g/dL; Ht: 31,20 \%; plaquetas: 657.000/ $\mathrm{mm}^{3}$; leucócitos: $15.460 / \mathrm{mm}^{3}$ (bastonetes: 4\%; segmentados: 52\%; eosinófilos: 5\%; linfócitos: $37 \%$; monócitos: $2 \%$ ); anisocitose ++ , microcitose ++ , hipocromia +++ . Observação: poiquilocitose: ++ ;

- Radiografia da perna esquerda: fratura oblíqua na diáfise da tíbia com formação de calo ósseo e desvio anterior (Figura 5);

- Eletroneuromiografia de membros superiores e inferiores: normal;

- Ressonância magnética de joelho direito: tíbia com lesão na região metafisária medial, estendendo-se à epífise (Figura 6).

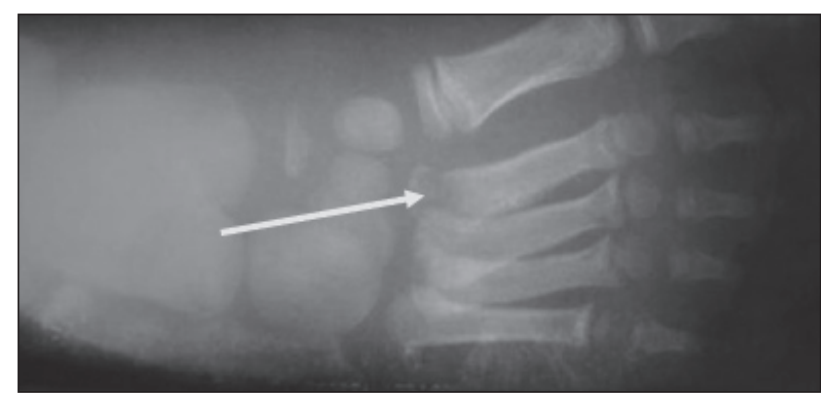

Figura 3 - Radiografia do pé direito do paciente A. Lesão osteolítica na base do segundo metatarso.

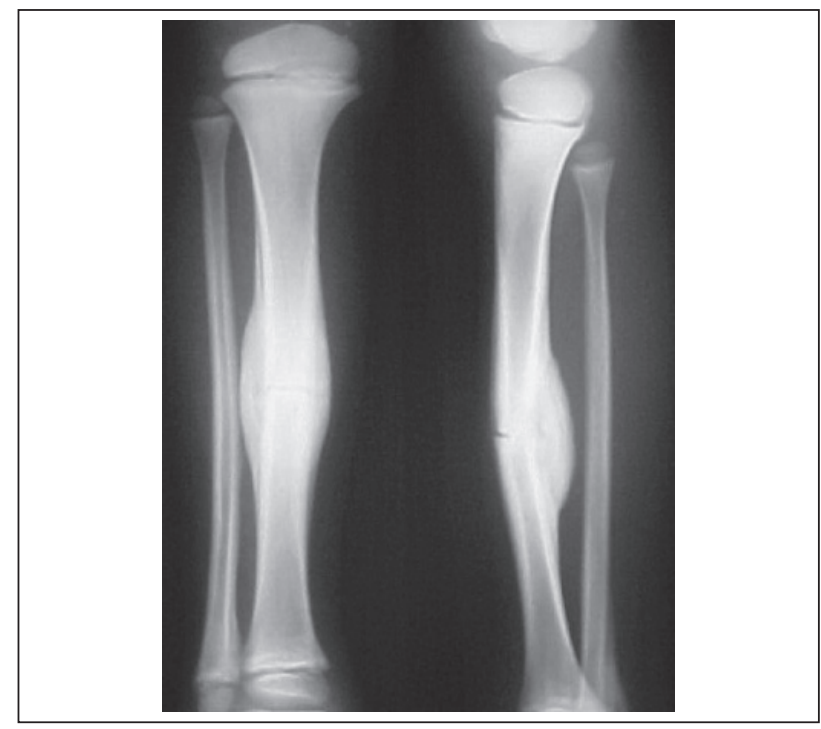

Figura 4 - Radiografia da perna direita do paciente A. Fratura transversa na diáfise da tíbia com formação de calo ósseo. 


\section{Evolução e tratamento}

Paciente com diagnóstico inicial de analgesia congênita mais celulite na região poplítea esquerda, fratura no terço médio da tíbia esquerda, deformidade em varo decorrente de fratura epifisária, anemia e hiperatividade.

Foi submetido a tratamento com cefalotina $(500 \mathrm{mg}$, de $6 / 6 \mathrm{~h}$ ) por sete dias com regressão da celulite em 16 dias, além de curativos e imobilização adequada.

Após 50 dias, o paciente retornou para acompanhamento em bom estado geral e extremamente agitado. A lesão da região poplítea esquerda encontrava-se com bom aspecto, sem sinais flogísticos.

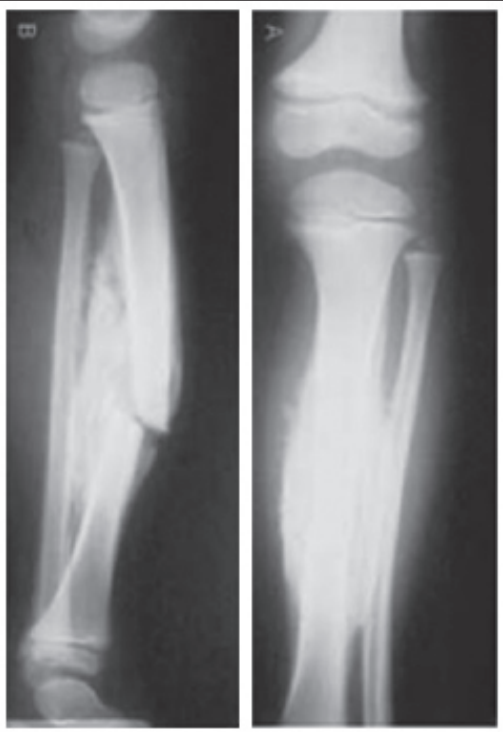

Figura 5 - Radiografia da perna esquerda do paciente B. Fratura oblíqua na diáfise da tíbia.

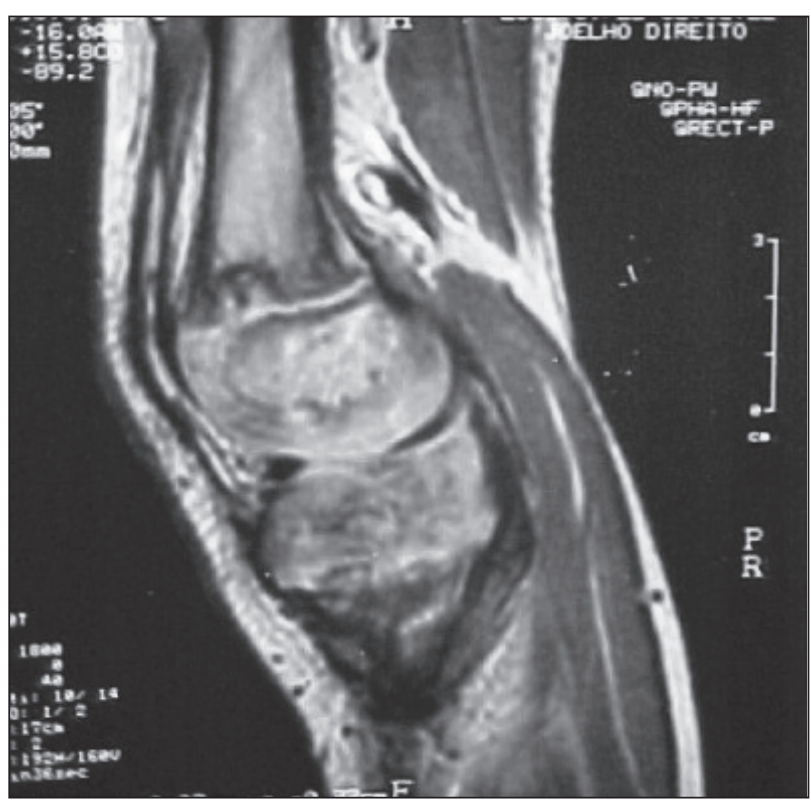

Figura 6 - Ressonância magnética do joelho direito do paciente $B$. Lesão na região metafisária medial estende-se à epífise.

\section{Discussão}

A HSAN é uma condição em que neurônios, tanto sensitivos quanto autonômicos, não se desenvolvem ou tornam-se atróficos ou degenerados. Dyck et al. ${ }^{1}$ propuseram uma classificação mostrada no Quadro I.

As características clínicas variam de acordo com cada tipo de HSAN. Nossos pacientes são semelhantes àqueles do tipo HSAN IV (analgesia congênita), mas, por apresentarem sudorese e inteligência normais, classificamos ambos os irmãos como HSAN tipo V. Este tipo caracteriza-se por perda seletiva da sensibilidade à dor e a estímulos térmicos, principalmente nas extremidades, força muscular normal, reflexos tendinosos preservados, inteligência normal, podendo ocorrer disfunção sudomotora, mas sem anidrose ${ }^{1}$.

Em relação aos aspectos osteoarticulares, Szöke et al. ${ }^{4}$ relatam que fraturas ocorrem em 100\% dos casos após os primeiros anos de vida. Diversas outras complicações são frequentes, tais como acro-osteólise, articulação de Charcot, osteomielites, luxações, deformidades articulares, necrose avascular e amputações ${ }^{4-10}$.

A sobrevida dos pacientes é variável, sendo os de maior idade relatados na literatura: uma mulher de 40 anos que desenvolveu artropatia de Charcot em ambos os ombros por andar com as mãos, devido a amputações dos membros inferiores ${ }^{11}$, e um homem de 68 anos $^{12}$.

O diagnóstico diferencial pode ser realizado por meio das características clínicas típicas de cada doença. Hilz et al..$^{5}$ defende a realização de biópsias de pele e nervos periféricos, testes de estimulação simpática e análise do DNA para a confirmação diagnóstica.

$\mathrm{O}$ mecanismo fisiopatológico da analgesia congênita continua inexplicado. Em recente estudo, Miranda et al. ${ }^{13}$ sugerem que mutações

Quadro I - Neuropatia autonômica sensitiva hereditária (HSAN)

\begin{tabular}{|c|c|c|}
\hline Tipo & Características principais & Herança \\
\hline $\begin{array}{l}\text { HSAN I (neuropatia } \\
\text { radicular sensitiva } \\
\text { hereditária) }\end{array}$ & $\begin{array}{l}\text { Analgesia no pé e } \\
\text { complicações teciduais } \\
\text { relacionadas. }\end{array}$ & $\begin{array}{l}\text { Autossômica } \\
\text { dominante }\end{array}$ \\
\hline $\begin{array}{l}\text { HSAN II (neuropatia } \\
\text { sensitiva congênita) }\end{array}$ & $\begin{array}{l}\text { Instalação precoce de } \\
\text { perda de sensações em } \\
\text { todas as modalidades. } \\
\text { Início da doença na } 1^{\text {a }} \text { e } 2^{\text {a }} \\
\text { décadas. }\end{array}$ & $\begin{array}{l}\text { Autossômica } \\
\text { recessiva }\end{array}$ \\
\hline $\begin{array}{l}\text { HSAN III (diasautonomia } \\
\text { familiar ou síndrome de } \\
\text { Riley-Day) }\end{array}$ & $\begin{array}{l}\text { Instalação precoce, } \\
\text { sintomas autonômicos } \\
\text { predominantes e ausência } \\
\text { das papilas fungiformes. }\end{array}$ & $\begin{array}{l}\text { Autossômica } \\
\text { recessiva, } \\
\text { predominante em } \\
\text { judeus (gene em } \\
\text { D9S58) }\end{array}$ \\
\hline $\begin{array}{l}\text { HSAN IV (neuropatia } \\
\text { sensitiva familiar com } \\
\text { anidrose ou analgesia } \\
\text { congênita) }\end{array}$ & $\begin{array}{l}\text { Retardo mental discreto, } \\
\text { episódios de febre } \\
\text { relacionados ao ambiente } \\
\text { (não somente por } \\
\text { infecção). }\end{array}$ & $\begin{array}{l}\text { Autossômica } \\
\text { recessiva (rara) }\end{array}$ \\
\hline $\begin{array}{l}\text { HSAN V (neuropatia } \\
\text { sensitiva familiar } \\
\text { com perda seletiva } \\
\text { de pequenas fibras } \\
\text { mielinizadas) }\end{array}$ & $\begin{array}{l}\text { Analgesia congênita, } \\
\text { força muscular, reflexos } \\
\text { tendinosos normais } \\
\text { e anormalidades na } \\
\text { nocicepção. }\end{array}$ & $\begin{array}{l}\text { Autossômica } \\
\text { recessiva }\end{array}$ \\
\hline
\end{tabular}

Fonte: Dyck et al. 
nos genes de dois receptores nervosos (receptor tipo I da tirosinaquinase - NTRK1 e receptor do fator de crescimento do nervo) podem alterar o processo de autofosforilação e reduzir a atividade do receptor.

Atualmente, houve maiores avanços nos estudos relacionados à origem genética das $\mathrm{HSAN}^{13}$, que confirmam os tipos descritos por Dyck et al. ${ }^{1}$ e propõem subtipos para os mesmos.

Szöke et al. ${ }^{4}$ notaram que, após análise de 19 casos com complicações osteoarticulares, em $80 \%$ o lado esquerdo foi o primeiro a ser acometido, principalmente os membros inferiores, e $75 \%$ de todas as fraturas acometiam o lado esquerdo.

Devido à ocorrência de múltiplas fraturas é comum a suspeita, nesses pacientes, de síndrome de Silverman ${ }^{14}$ ou síndrome da criança espancada, sendo o fato erroneamente relatado às autoridades, causando mais problemas ao paciente com analgesia congênita e seus familiares, inclusive de natureza social e policial.

Assim, a analgesia congênita é uma doença rara, de alta morbidade, gerando graves complicações osteoarticulares 5 .

O tratamento cirúrgico deve ser adequado a cada complicação e sua gravidade. Infecções estabelecidas devem ser tratadas com desbridamento cirúrgico amplo. Deformidades podem ser corrigidas com osteotomias ou episiodeses. Luxações são mais bem tratadas de modo conservador. O tratamento ortopédico cirúrgico é difícil, portanto, deve ser enfatizada cada vez mais a prevenção das lesões ósseas e articulares, evitando-se, ao máximo, a necessidade de amputações ${ }^{4,15}$.

Durante procedimentos cirúrgicos, deve-se ter bastante cuidado com a anestesia, pois os reflexos cardiovasculares estão preservados. A temperatura deve ser monitorizada e controlada com ajuste da temperatura da sala, uso de cobertores térmicos, frios se necessário, uma vez que esses pacientes podem apresentar hipertermia. A anestesia geral é, na maioria das vezes, preferida, principalmente nos pacientes com retardo mental ${ }^{16}$.

Deve-se destacar que o tratamento multidisciplinar torna-se essencial para o acompanhamento do paciente, permitindo um correto aprendizado proprioceptivo e um desenvolvimento físico e psíquico adequado 5 .

Trata-se de dois relatos de criança do sexo masculino, de quatro e seis anos de idade, consanguíneos e que apresentam doença em estágio avançado. Destaca-se que é um quadro clínico raro, porém com necessidade de ser hipotetizado quando da avaliação clínica diferencial. Ainda constitui-se numa doença grave e que deve ser divulgada e tratada por equipe multidisciplinar, além do acompanhamento contínuo durante toda vida do portador. Sugere-se que esses pacientes sejam acompanhados regularmente por equipes do programa de saúde da família.

\section{Referências}

1. Dyck PJ, Thomas PK, Griffen JW. Peripheral neuropathy. $3^{\text {rd }}$ ed. Philadelphia: W. B. Saunders; 1993. p.1065-93.

2. Greider TD. Orthopedic aspects of congenital insensitivity to pain. Clin Orthop Relat Res. 1983;(172):177-85.

3. Dearborn G. A case of congenital general pure analgesia. The Journal of Nervous and Mental Disease. June 1932;75(6):612-615.

4. Szöke G, Rényi-Vámos A, Bider MA. Osteoarticular manifestations of congenital insensitivity to pain with anhydrosis. Int Orthop. 1996;20(2):107-10.

5. Hilz MJ, Stemper B, Axelrod FB. Sympathetic skin response differentiates hereditary sensory autonomic neuropathies III and IV. Neurology. 1999;52(8):1652-7.

6. Schulman H, Tsodikow V, Einhorn M, Levy Y, Shorer Z, Hertzanu Y. Congenital insensitivity to pain with anhidrosis (CIPA): the spectrum of radiological findings. Pediatr Radiol. 2001;31(10):701-5.

7. Bar-OnE, Weigl D, Parvari R, Katz K, Weitz R, Steinberg T. Congenital insensitivity to pain. Orthopaedic manifestations. J Bone Joint Surg Br. 2002;84(2):252-7.

8. Lejman T, Sulko J. [Orthopedic problems in children with congenital insensitivity to pain]. Chir Narzadow Ruchu Ortop Pol. 1999;64(2):169-75.

9. Herdem M, Polat S, Ozbarlas S, Onaç E. Congenital insensitivity to pain with anhidrosis: a case report. Int Orthop. 1998;22(2):139-40.
10. Bronfen C, Bensahel H, Teule JG. [Orthopedic aspects of congenital insensitivity to pain]. Chir Pediatr. 1985;26(3):193-6.

11. Guille JT, Forlin E, Bowen JR. Charcot joint disease of the shoulders in a patient who had familial sensory neuropathy with anhidrosis. A case report. J Bone Joint Surg Am. 1992;74(9):1415-7.

12. Sipahi T, Okumu N, Sahin F, Kuyucu N, Tan E, Gürer Y. Congenital insensitivity to pain with anhidrosis: report of a 68-day-old case. Eur $J$ Pediatr. 1999;158(3):268-9.

13. Miranda C, Di Virgilio M, Selleri S, Zanotti G, Pagliardini S, Pierotti MA et al. Novel pathogenic mechanisms of congenital insensitivity to pain with anhidrosis genetic disorder unveiled by functional analysis of neurotrophic tyrosine receptor kinase type $1 /$ nerve growth factor receptor mutations. J Biol Chem. 2002;277(8):6455-62.

14. Tachdjian M.O. Pediatric orthopaedics. $2^{\text {nd }}$ ed. Philadelphia: W. B. Saunders; 1990.

15. Bronfen C, Bensahel H, Teule JG. [Orthopedic aspects of congenital insensitivity to pain]. Chir Pediatr. 1985;26(3):193-6.

16. Oliveira CR, dos Santos FA, Nogueira CS, Mainardes EJ. Spinal anesthesia in a patient with congenital insensitivity to pain with anhidrosis. Anesth Analg. 2007;104(6):1561-2. 